\title{
Preparation of Zeolite Cross-linked Chitosan and Adsorption for Copper(II) and Iron(III)
}

\author{
Zengxin $\mathrm{Li}^{\mathrm{a}, 1}$,Yuehuan Yuan ${ }^{\mathrm{b}}$,Lili Xing ${ }^{\mathrm{c}}$,Yujuan Ma and Rutao Wang \\ College of Chemistry and Chemical Engineering Qingdao University, Qingdao, China \\ alizx57@126.com, b957576417@qq.com
}

\begin{abstract}
Keywords: Chemical adsorption; Zeolite; Chitosan; Copper(II); Iron(III);Waste water pollution
\end{abstract}
\begin{abstract}
Copper and iron ions are common heavy metal ions in industrial wastewater, pollution can be caused by the direct emissions of wastewater to the environment, only when waste water reach the standard that it can be let out. Zeolite cross-linked chitosan composite adsorbent using natural raw materials, reduce the copper and iron ion content in industrial waste water by physical adsorption. The composite adsorbent made of by zeolite cross-linked chitosan (5:1) is prepared by this experiment. The adsorbent in neutral liquids under room temperature, copper iron adsorption rate was $15.8 \%$, and the iron ions adsorption rate was $65.5 \%$.Electroplating factory and smelters electrolytic workshop produce a large amount of wastewater containing copper, iron, if not handled pollution to living environment will be caused. In recent years, the concentration of the dispose of copper iron in wastewater is to look for more suitable, new low-cost adsorption material.
\end{abstract}

\section{Introduction}

Zeolite is a kind of aqueous potassium, sodium, calcium and barium, aluminum silicate minerals, has a special porous structure, a good adsorption performance, but the pure zeolite has little adsorption of copper and iron. Chitosan is a deacetylation product of chitin, because chitosan molecules containing hydroxyl, amino and many kinds of active functional groups, it has strong ability to complex ability it can be used as a ligand of copper and iron to form chelate. According to the zeolite adsorption characteristics of heavy metal ions, make use of the character that chitosan in acidic solution has positive charge, make the chitosan load on the zeolite, combining cheap zeolite and chitosan can improve the efficiency of adsorption can reduce the amount of chitosan, reduce cost, the composite adsorbent can be used for processing copper liquid iron wastewater .The experiment actives the zeolite by acidification, then it is loaded by the chitosan that deacetylation rate is more than $96 \%$,so the composite adsorbent is obtained. Adopting the method of the control of single variable to do the experiment of the adsorption of copper iron ion to determine the best concentration temperature, concentration, and time. The target of the experiment is to explore green method of adsorbing copper iron ion in wastewater, the method not only reduce the cost but also improve the efficiency of the adsorption, meets the require of modern green chemistry.

\section{Experiment Materials and Instrument}

Zeolite powder, white undressed ore sample. Natural zeolite is a kind of aqueous potassium, sodium, calcium and barium, aluminum silicate minerals.

Chitosan, [(1, 4) - 2 - amino - 2 - deoxidation - beta - D - glucan], chitin is [(1, 4) - 2 - acetyl amino - 2 - deoxidation - beta - D - glucan] which is the natural macromolecule whose rate of deacetylation is more than $70 \%$. Translucent or white flakes.

Pure copper sulfate analytically pure; Ferrous sulfate analytically pure ; Acetic acid analytically pure

Sodium hydroxide analytically pure; Sulfuric acid analytically pure;Hydrochloric acid analytically pure; Orthophenanthroline analytically pure; The beaker (100 ml to $100 \mathrm{ml} 500 \mathrm{ml})$;

${ }^{1}$ corresponding author 
Volumetric flask (250 ml);Colorimetric tube (25 ml); Pipette (25 ml);A pipette (10 ml); Measuring cylinder (10 ml $50 \mathrm{ml})$

Type 721 spectrophotometer ; Thermostatic water bath pot;800 type centrifugal precipitator ; Electronic balance Model: FA2104S; Thermostatic drum wind drying oven Model: GZX - GF MBS - I

\section{The preparation of adsorbent}

Zeolite activation: $50 \mathrm{~g}$ zeolite in crucible, heating at $400^{\circ} \mathrm{C}, 1 \mathrm{~h}$, take out and put it in the dryer after cooling to room temperature. Add $3 \mathrm{~mol} \cdot \mathrm{L}^{-1}$ of sulfuric acid, constant temperature for $2 \mathrm{~h}$ at $80^{\circ} \mathrm{C}$, and then filter separation, washing clean .Put in a concentration of $10 \%$ oxalic acid solution, stirring at room temperature for $2 \mathrm{~h}$, washing and drying.

The preparation of chitosan sol: take $1 \mathrm{~g}$ of chitosan, the decollation degree is $95 \%$, add it to $25 \mathrm{ml}$ of acetic acid solution (1\%), stirring, heating it. At room temperature it is sol with pale yellow viscosity.

Adsorbent preparation: weigh activated zeolite $5 \mathrm{~g}$, slowly add it to chitosan sol, heat for $1 \mathrm{~h}$,stir, and put samples into oven at $110{ }^{\circ} \mathrm{C}$ to constant weight, grinding and screening.

\section{Experiment and Result Analysis}

\section{Determination of copper ions}

(1) Test of adsorption time

Take $200 \mathrm{ml}$ copper ion solution in a certain concentration, add suitable amount of zeolite adsorbents, stir well, and then statically adsorb. Every hour, undergo a stirring sampling, take $10 \mathrm{ml}$ in the centrifugal pipe and go centrifugal separation, using spectrophotometry ion to concentrate. Take eight sample in total, make an absorbance - time diagram 1.

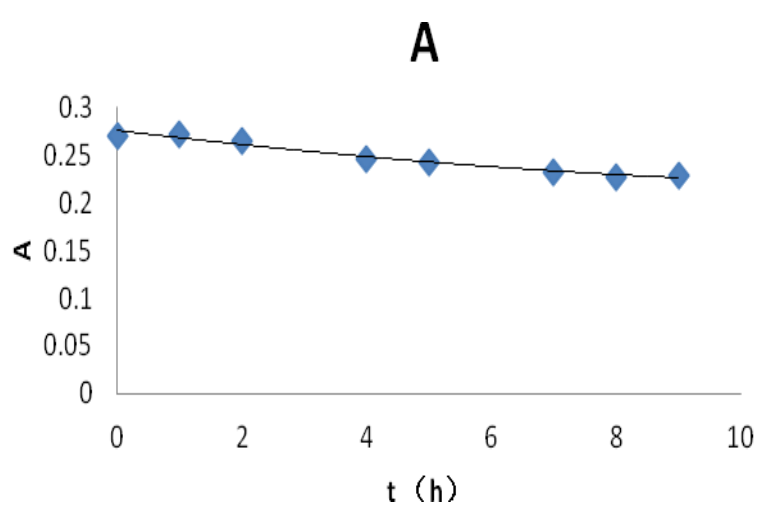

Fig. 1 Curves of absorbance and time

Absorbance continue to decrease as time goes, but the falling range slows, by lambert beer's law, Absorbance as time falling drop after 8 hours slow, by lambert beer's law, the absorbance is smaller, the lower the concentration of metal ions, the adsorption at $t=8$ (h) to large extent.

(2) Test of adsorption time

Take $100 \mathrm{ml}$ of copper ion solution on four beakers, adding equal amount of zeolite adsorbent respectively, stir well, statically adsorb , after two hours take liquid and go centrifugation, determine absorbance, make the diagram 2 . 
A

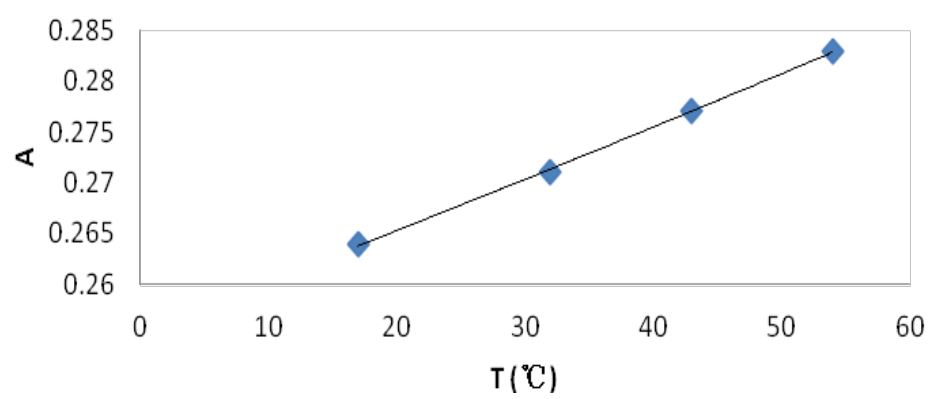

Fig. 2 Curve of absorbance an temperature $\left({ }^{\circ} \mathrm{C}\right)$

The diagram2 indicates that as temperature goes up, the adsorption increase as well. So the adsorption is suitable in low temperature, but the adsorption goes in room temperature, it could also have a good result.

(3) The test of suitable $\mathrm{pH}$

Take $100 \mathrm{ml}$ of copper ion solution in six beaker, respectively adjust $\mathrm{pH}$ to 3, 4, 5, 6, 7, 8, stirring well, adding suitable amount of adsorbent, statically adsorb. Two hours later, take samples and go centrifugation. Make diagram 3.

A

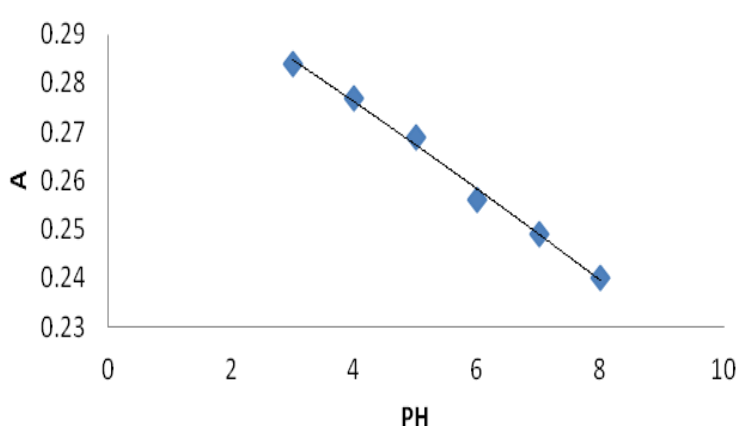

Fig.3 Curves of absorbance and pH

By Fig. 3, absorbance has a minimum value as $\mathrm{pH}$ change in the $\mathrm{pH}$ between $6.0-8.0$, thus to achieve a better adsorption effect, solution $\mathrm{pH}$ should be controlled between 6.0 to 8.0.

\section{Test of iron ions}

(1) Test of adsorption time

Take $100 \mathrm{ml}$ of a certain concentration of iron ion solution , adding suitable amount of zeolite adsorbents, stir well, statically adsorb .Every half an hour, stir sample, take $10 \mathrm{ml}$ in the centrifugal pipe and go centrifugal separation, using spectrophotometry to test ion concentration. Take seven sample , make diagram absorbance - time 4. 
A

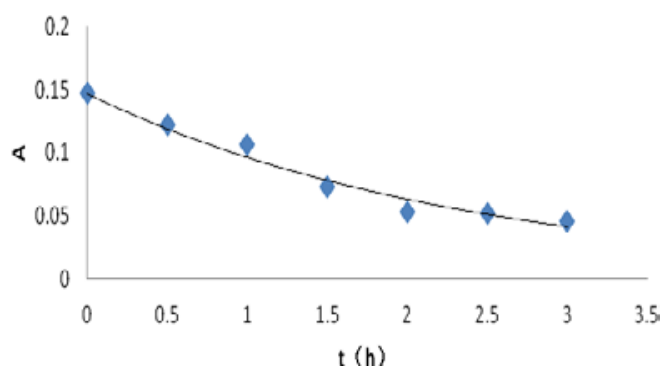

Fig.4 Curves of absorbance and time

By Fig.4, when time is 120min, adsorption goes slow, so $120 \mathrm{~min}$ is the best time for the composite adsorption to adsorb iron ions.

(2) Test of adsorption temperature

Take $100 \mathrm{ml}$ iron ions solution in 3 beakers, respectively add equal amount of zeolite adsorption, stir well, and statically adsorb. After two hours, take samples and go centrifugation, after complexing test the adsorption curve5.

A

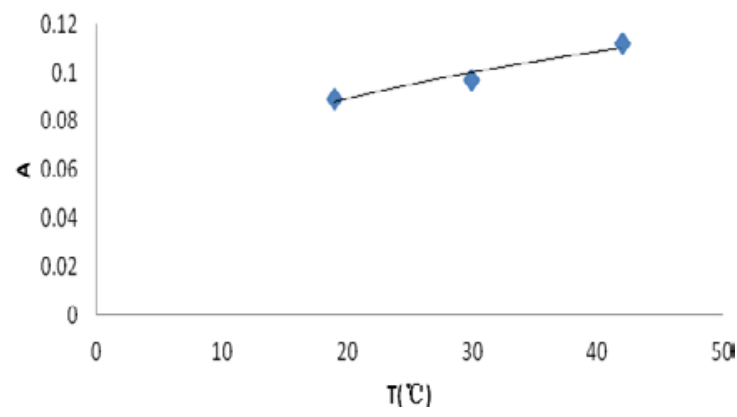

Fig.5 Curve of absorbance an temperature $\left({ }^{\circ} \mathrm{C}\right)$

By Fig.5, as time increase absorbance goes up slowly, so low temperature is better. But take all in account, the room temperature is suitable.

(3) The test of adsorption $\mathrm{pH}$

Take $100 \mathrm{ml}$ iron ion solution in six beaker, respectively adjust $\mathrm{pH}$ to $2,3,5,7,11,13$, stirring evenly, adding suitable amount of adsorbent, statically adsorb.

Two hours later take supernatant fluid for centrifugal sample processing, after complexing, determinate of absorbance.

A

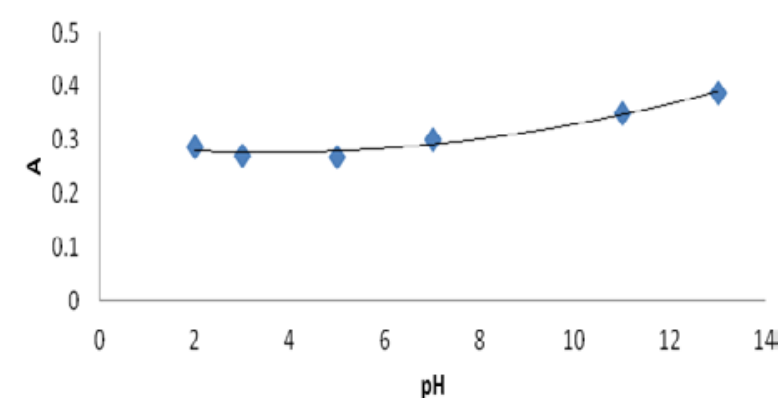

Fig.6 Curves of absorbance and $\mathrm{pH}$

By Fig. 6, absorbance is relatively flat, along with the change of $\mathrm{pH}$. But when $\mathrm{pH}$ is about 4.0, the absorbance is obviously low, so the best $\mathrm{pH}$ is 4.0 . 


\section{Adsorption rate}

At the best conditions that is tested above, test the adsorption rate.

Before adsorption: absorbance is $c_{0}$.

According to the formula: $\mathrm{A}=\left(c_{0}-c\right) / c_{0} * 100 \%$,the adsorption rate of composite materials can get, $c_{0}$ and $c$ represents the concentration of metal ions before and after adsorption ,the unit is mmol - $\mathrm{L}^{-1} ; \mathrm{V}$ is the volume of mental ions solution, the unit is $\mathrm{L}$.

The final adsorption is $15.8 \%$ ( copper ions) and $65.5 \%$ (iron ions).

\section{Conclusion}

In the experiment, the composite adsorbent is prepared by zeolite crosslinking chitosan. The adsorption is in neutral liquids at temperature, the adsorption rate of copper can reach $15.8 \%$ after 8 hours, and the adsorption rate of iron can reach $65.5 \%$ after 2 hours.

\section{Reference}

[1] Berkeley R. C. W. Chitin, chitosan and their degradative enzymes. In Microbial Polysaccharides, ed. New York. Academic Press, 1979, p. 205-236.

[2] Kurita K., Koyama Y., Taniguchi A. J. Appl. Polymer Sci. Vol. 31(5)(1986) , p. 1169-1176.

[3] Pang Sujuan, Li Liangquan. Journal of Hainan University (Natural Science Edition), Vol. 16 (3) (1998) , p. 220-223

[4] Peng Changhong, Wang Yuting, Chen Ge, et al. Environmental Science, Vol. 19 (5) (1998), p. 29-33

[5] Wang Yudu, Chen Ge, Zhu Hai, et al. Environmental Pollution and Control, Vol.20 (1) (1998), p. 1-3

[6] Zhang Lanying, An Shengji, Zheng Songjie, et al. Journal of Changchun University of Science and Technology, Vol. 29 (2) (1999) , p. 199 - 197

[7] Zhao Daqing, Sun Lanping, Xu Hui, et al. Journal of Environment and Health, Vol. 25 (11) (2008), p. 979-982. 